\title{
Analisis Retensi Rekam Medis Rawat Jalan Aktif Ke Inaktif Di UPT Puskesmas Sukarasa
}

\author{
Novi Indriyani Gunawan ${ }^{1}$, Meita Nurseha Oktaviani ${ }^{2}$, Meira Hidayati ${ }^{3}$ \\ ${ }^{1,2,3}$ Program Studi D-3 Rekam Medis dan Informasi Kesehatan, Politeknik Piksi Ganesha Bandung
}

\begin{tabular}{l}
\hline Article Info \\
\hline Article history: \\
Received Jun 23, 2021 \\
Revised Jul 22, 2021 \\
Accepted Jul 23, 2021 \\
\hline
\end{tabular}

Keywords:

Retention

Medical Record File

SOP

\begin{abstract}
Medical record retention is an activity of transferring medical record documents from an active storage room to an inactive storage room. Based on a preliminary survey at UPT Puskesmas Sukarasa, it is known that the puskesmas has retained outpatient medical record files 2 times in 2018 and 2019. But the retention is not done according to the SOP. The purpose of the study was to determine the implementation of outpatient medical record file retention at UPT Puskesmas Sukarasa. This type of research is descriptive with a retrospective approach. The research instrument was carried out by observation, interviews and checklist forms. The object of the research is the implementation of active to inactive outpatient medical record retention at UPT Puskesmas Sukarasa. The research subjects are the officer in charge of medical records and the person in charge of registration who performs retention of outpatient medical records.It is also known that the UPT Puskesmas Sukarasa already has an SOP on retention of medical records, but the SOP has not been implemented due to the lack of special staff for retention and the accumulation of medical record files on active storage shelves. Files that are retained are files for 2016-2018 without looking at the last date of treatment but based on the year number in the medical record file. Then the file is immediately moved to the inactive storage rack. It can be concluded that the implementation of retention at UPT Puskesmas Sukarasa is not in accordance with the SOP. It would be better if the retention is carried out according to the SOP with special and scheduled officers so that there is no accumulation of medical record files.
\end{abstract}

This is an open access article under the CC BY-SAlicense.

\section{Corresponding Author:}

Novi Indriyani Gunawan,

Prodi D-3 Rekam Medis dan Informasi Kesehatan,

Politeknik Piksi Ganesha Bandung,

Jl. Jl.Jend. Gatot Subroto 301 Bandung 40274, Jawa Barat.

Email: nigunawan@piksi.ac.id

\section{PENDAHULUAN}

Puskesmas merupakan tempat pengobatan yang paling mudah dikunjungi oleh masyarakat karena setiap kecamatan memiliki satu puskesmas. Selain itu dilihat dari biaya pun tidak terlalu mahal. Seiring dengan berkembangnya tingkat pendidikan masyarakat maka puskesmas diharapkan dapat memberikan pelayanan yang optimal agar masyarakat merasa puas dan mendapatkan jasa pelayanan yang maksimal. 
Dalam upaya memberikan pelayanan yang optimal kepada setiap pasien yang berkunjung baik itu pasien rawat jalan atau rawat inap maka harus adanya pencatatan identitas pasien yang biasa disebut rekam medis. Rekam medis yaitu kegiatan administrasi medis di klinik, puskesmas, ataupun rumah sakit untuk menunjang kegiatan pelayanan kesehatan yang lebih rinci. Hal tersebut merujuk pada data diri seorang pasien dan segala hasil pemeriksaan atau diagnosa yang dilakukan petugas medis baik itu dokter atau dokter gigi, perawat dan petugas lainnya. Kemudian hasil yang didapat dari pemeriksaan ditulis ke dalam rekam medis. Rekam medis berisi keterangan, catatan dan dokumen pasien secara lengkap meliputi identititas pribadi, sosial dan hal-hal lain yang mendeskripsikan pasien tersebut. Keterangan dan catatan pasien mencakup identitas pasien, petugas medis yang bertanggungjawab, pelayanan yang didapatkan selama pasien berada di fasilitas kesehatan, diagnosa penyakit pasien, waktu pasien dilayani, dan tindakan lain yang diberikan kepada pasien. Rekam medis pasien merupakan tanggung jawab setiap pemberi pelayanan termasuk petugas perekam medis oleh sebab itu sifat rekam medis adalah rahasia karena tidak bisa diakses oleh semua orang sebab menyangkut data diri dan riwayat penyakit seseorang.

Rekam medis yang telah memuat data pasien disimpan diruang rekam medis yang bilamana pasien datang untukberobat kembali berkas tersebut dapat diambil oleh petugas rekam medis.Pelayanan di puskesmas terbagi menjadi dua yaitu pelayanan pasien rawat inap dan pasien rawat jalan. Berdasarkan hasil wawancara dengan petugas di Puskesmas Sukarasa bahwa pelayanan yang tersedia hanya pelayanan rawat jalan saja yang artinya bentuk pelayanan yang diberikan kepada pasien dilingkungan puskesmas tanpa harus menginap. Dengan adanya pelayanan rawat jalan tersebut menjadikan berkas rekam medis hal yang sangat penting guna menunjang pelayanan yang efektif dalam hal pencatatan identitas pasien maupun riwayat penyakit pasien.

Berdasarkan hasil wawancara dengan petugas rekam medis di Puskesmas Sukarasa, rekam medis tersebut disimpan di ruangan khusus dengan rak penyimpanan terbatas yang terbagi menjadi rak penyimpanan aktif dan rak penyimpanan inaktif.

Berkas rekam medis tersebut tidak akan selamanya disimpan dirak penyimpanan aktif, karena akan terjadi penumpukan berkas rekam medis dirak tersebut. Rekam medis harus disimpan sesuai dengan peraturan yang telah dibuat sebelumnya yaitu masa simpan rekam medis dirak penyimpanan aktif di pelayanan selain rumah sakit maksimal dua tahun. Maka disediakan rak penyimpanan inaktif agar berkas rekam medis yang telah melewati batas maksimalnya dipindahkan ke rak tersebut sesuai peraturan yang berlaku.

Dengan adanya peraturan tersebut maka perlu adanya penyusutan berkas rekam medis atau biasa disebut retensi rekam medis. Menurut BPPRM (Buku Pedoman Penyelenggaraan Rekam Medis) tahun 2006, retensi memiliki pengertian yaitu suatu kegiatan memisahkan atau memindahkan antara dokumen rekam medis inaktif dengan dokumen rekam medis yang masih aktif di ruang penyimpanan (filing) [1]. Retensi ini berguna untuk mengurangi jumlah formulir yang ada di dalam berkas rekam medis. Pengurangan dilakukan dengan cara menyortir satu persatu dan melihat berkas tersebut mempunyai nilai guna atau tidak. Jika memiliki nilai guna maka akan disimpan kembali dan jika tidak memiliki nilai guna maka akan dilanjutkan ke tahap selanjutnya. Penyusutan atau retensi di puskesmas bisa dilakukan sesuai dengan standar operasinalprodesur yang ada di puskesmas. Penyusutan dilakukan untuk mengurangi penumpukan berkas rekam medis diruang penyimpanan agar rekam medis selalu tertata rapi dan rekam medis mudah ditemukan oleh petugas.

Berdasarkan wawancara dengan petugas penanggung jawab Rekam Medis UPT Puskesmas Sukarasa, bahwa di UPT Puskesmas sukarasa sudah memiliki SOP tertulis tentang Retensi Berkas Rekam Medis berdasarkan Surat Keputusan Kepala UPT 
Puskesmas Sukarasa nomor 014/SK-1/UKP8/UPT PKM SKRS/2019 tentang Rekam Medis [2].

Telah diketahui bahwa UPT Puskesmas Sukarasa sudah melakukan retensi pertama kali tahun 2018 dan untuk kedua kalinya pada tahun 2019. Tetapi tidak sesuai dengan SOP dikarenakan keterbatasan petugas dan adanya penumpukan berkas rekam medis di ruangan rak penyimpanan aktif. Oleh karena itu retensi pada tahun 2019 dilakukan dengan langsung memindahkan semua berkas rekam medis tahun 2016-2018 ke rak penyimpanan inaktif.

Berdasarkan latar belakang tersebut maka peneliti akan mengambil judul penelitian yaitu "Analisis Retensi Rekam Medis Rawat Jalan Aktif ke Inaktif di UPT Puskesmas Sukarasa". Tujuan umumnya untuk mengetahui pelaksanaan retensi berkas rekam medis pasien rawat jalan di UPT Puskesmas Sukarasa.

\section{METODE PENELITIAN}

Penelitian ini dilakukan menggunakan pendekatan retrospektif yaitu pendekatan berdasarkan data-data yang sudah ada atau data masa lampau [3] dan menggunakan metode penelitian deskriptif, yaitu suatu metode yang digunakan untuk menggambarkan atau menganalisis suatu hasil peneliti tetapi tidak digunakan untuk membuat kesimpulan lebih luas [4, p. 147]. Dalam penelitian ini peneliti menggunakan data pada bulan Januari tahun 2019 sebanyak $\leq 20.000$ berkas rekam medis yang diretensi dari penyimpanan aktif ke penyimpanan inaktif di UPT Puskesmas Sukarasa.

Subyek atau responden penelitian adalah pihak yang digunakan sebagai sampel penelitian ini [5], yaitu petugas penanggung jawab rekam medis dan penanggung jawab pendaftaran yang melakukan retensi aktif ke inaktif di UPT Puskesmas Sukarasa. Obyek penelitian adalah suatu atribut yang memiliki nilai atau sifat unik lalu ditentukan dan dipilih oleh seorang peneliti untuk diamati, dipelajari sehingga mendapatkan kesimpulan dari suatu fenomena [4, p. 39]. Obyek pada penelitian ini yaitu kegiatan pelaksanaan retensi berkas rekam medis aktif ke inaktif di UPT Puskesmas Sukarasa.

Pemilihan informan dilakukan dengan cara purposive sampling yaitu yakni pengambilan sampel berdasarkan kapasitas dan kapabelitas atau yang berkompeten dan benar-benar paham di bidangnya di antara anggota populasi [6, p. 64]. Pemilihan informan dalam penelitian ini berjumlah 2 orang, yaitu lulusan D3 Rekam Medis yang melakukan pelaksanaan Retensi rawat jalan aktif ke inaktif di UPT Puskesmas Sukarasa.

Instrumen penelitian yaitu alat yang digunakan sebagai pedoman dalam mengukur gejala alam ataupun sosial yang diamati [4, p. 102]. Instrumen penelitian yang digunakan dalam hal ini yaitu pedoman wawancara dengan check list observasi yang telah dibuat sebelumnya oleh peneliti tentang retensi. Analisis penelitian ini secara deskriptif menggunakan hasil yang diperoleh dari wawancara.

\section{HASIL DAN PEMBAHASAN}

\subsection{Hasil}

\section{Kebijakan Retensi Berkas Rekam Medis}

Dari hasil wawancara dengan petugas rekam medis diketahui bahwa UPT Puskesmas Sukarasa dalam menjalankan tugas retensi berkas rekam medis rawat jalan dari aktif ke inaktif sudah diatur dalam SOP No.272/SOP/UKP-8/2019 tentang "Retensi Berkas Rekam Medis". Retensi rekam medis adalah kegiatan pemindahan file rekam medis aktif ke inaktif, dimana file tersebut disortir satu-satu untuk mengetahui formulir yang memiliki nilai guna yang bisa digunakan untuk keperluan puskesmas dalam penelitian atau pendidikan, dan tidak memiliki nilai guna dapat dipindah tempatkan ke bagian pemusnahan. Tujuannya sebagai acuan untuk penerapan langkah-langkah bagi petugas untuk melakukan penyusutan berkas rekam medis. 
Berdasarkan SOP tersebut, terdapat langkah-langkah penyusutan berkas rekam medis sebagai berikut:

1. Petugas memilih berkas rekam medis yang sudah disimpan sekurang-kurangnya 2 tahun terhitung dari tanggal terakhir berobat di rak penyimpanan.

2. Petugas memindahkan berkas rekam medisaktif ke rak penyimpanan rekam medis inaktif.

3. Simpan berkas rekam medis in aktif selama 2 tahun, jika setelah 2 tahun pasien tersebut tidak kembali berobat maka berkas rekam medis dapat dimusnahkan.

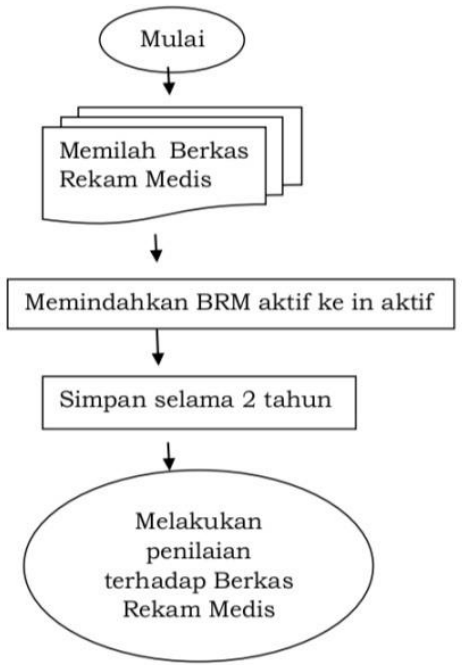

\section{Gambar 1. Flowchart Sistem Retensi Berkas Rekam Medis Rawat Jalan Aktif Ke Inaktif di UPT Puskesmas Sukarasa}

\section{Analisis Retensi Berkas Rekam Medis}

Berdasarkan data yang didapat dari petugas rekam medis, mengenai retensi berkas rekam medis aktif ke in aktif di ruang penyimpanan rekam medis. Petugas melaksanaan retensi sudah 2 kali pada tahun 2018 dan 2019. Berkas rekam medis pada tahun 2018 sudah dimusnahkan. Maka yang dapat di analisis hanya retensi pada bulan januari tahun 2019. Dalam pelaksanaan Retensi berkas Medis Di UPT Puskesmas Sukarasa tahun 2019 dilakukan oleh 2 orang petugas Rekam Medis yang sudah melapor kepada kepala UPT Puskesmas Sukarasa bahwa akan melakukan Retensi. Pelaksanaan retensi rekam medis pada tahun 2019 dilakukan petugas dengan cara:

1. Petugas melapor kepada kepala Puskesmas bahwa akan melakukan retensi berkas rekam medis aktif ke inaktif, untuk mendapatkan izin dan surat tugas.

2. Petugas memilah berkas rekam medis yang sudah melebihi masa simpan 2 tahun atau lebih di rak penyimpanan aktif, tanpa melihat tanggal terakhir berobat pasien.

3. Petugas memindahkan berkas rekam medis dari rak penyimpanan aktif ke rak penyimpanan inaktif.

Faktor Penyebab Ketidaksesuaian Standar Operasional Procedure Retensi Berkas Rekam Medis.

1. Sumber Daya Manusia

Salah satu faktor penyebab tidak terlaksanannya SOP Retensi Berkas Rekam Medis di UPT Puskesamas Sukarasa adalah sumber daya manusia.

2. Sarana Prasarana

Salah satu faktor tidak terlaksananya sesuai SOP adalah sarana prasarana. 


\subsection{Pembahasan}

\section{Kebijakan Retensi Berkas Rekam Medis}

Berdasarkan SOP No.272/SOP/UKP-8/2019 yang diterbitkan Puskesmas Sukarasa mengenai hal-hal pokok yang harus dilakukan oleh perekam medis dalam melakukan retensi dokumen rekam medis yaitu mengenai waktu simpan dokumen, pemindahan rekam medis aktif ke inaktif dan waktu penyimpanan rekam medis di rak inaktif. Hal tersebut sudah sesuai dengan Permenkes RI No. 269/MENKES/PER/III/2008 pasal 9 tentang rekam medis yang menyatakan bahwa berkas rekam medis maksimal disimpan selama 2 tahun di rak aktif dan inaktif [7]. Namun belum ada jadwal yang di tetapkan dalam SOP tersebut sehingga petugas rekam medis belum memiliki acuan yang baku mengenai waktu retensi, padahal jadwal retensi ini sangat penting agar pelaksanaan retensi bisa berjalan dengan baik dan dokumen bisa secepatnya tertata dengan rapi.

\section{Analisis Retensi Berkas Rekam Medis}

Dalam pelaksanaan retensi berkas medis di UPT Puskesmas Sukarasa pada tahun 2019 dilakukan oleh 2 orang petugas rekam medis yang sudah melapor kepada kepala UPT Puskesmas Sukarasa bahwa akan melakukan retensi. Sesudah diizinkan petugas melakukan retensi berkas rekam medis di ruang penyimpanan, sebagai berikut:

1. Petugas rekam medis pada tahun 2019 melakukan retensi pada berkas yang dibuat pada tahun 2016-2018 artinya ada berkas yang belum memiliki masa simpan 2 tahun tetapi sudah dilakukan retensi. Hal tersebut tidak sesuai dengan SOP No.272/SOP/UKP-8/2019 bahwa berkas di pilah sekurang-kurangnya dua tahun. Hal ini terjadi karena pada prosedur yang ditetapkan tidak terdapatnya jadwal retensi. Karena tidak ada jadwal yang jelas, retensi sering terjadi tidak sesuai prosedur [8].

2. Petugas Rekam medis melakukan retensi berkas rekam medis dilihat dari nomor tahun yang ada diberkas rekam medis. Nomor tahun tersebut berada diurutan paling belakang dari nomor rekam medis. Hal tersebut dilakukan untuk memudahkan petugas dalam melakukan retensi dan untuk memperbarui penomoran berkas rekam medis di tahun 2019. Petugas meretensi berkas rekam medis tahun 2016-2018. Retensi rekam medis dilakukan dengan cara langsung memindahkan semua berkas rekam medis tahun 2016-2018 tersebut dari rak penyimpanan aktif ke rak penyimpanan inaktif diruang penyimpanan bagian belakang. Dikarenakan petugas akan melakukan penataan ulang nomor rekam medis baru ditahun 2019 supaya tersusun rapih dan tidak adanya nomor rekam medis ganda. Hal tersebut tidak sesuai dengan SOP No.272/SOP/UKP-8/2019. Pada SOP tersebut seharusnya berkas rekam medis diretensi berdasarkan tanggal terakhir berobat.

3. Berkas Rekam Medis Inaktif dikumpulkan dan dijajarkan berdasarkan sistem penjajaran Middle Digit Filling dan tahun kunjungan pasien di rak penyimpanan Inaktif. Dan jika pasien berobat kembali ke UPT Puskesmas Sukarasa dan memiliki nomor rekam medis lama, maka nomor rekam medis di ganti dengan nomor rekam medis baru dengan sistem penjajaran Terminal Digit Filling, lalu petugas mencari berkas rekam medis lama ditempat penyimpanan inaktif. Setelah berkas rekam medis ditemukan maka data rekam medis lama disatukan dengan berkas rekam medis baru, jika tidak ditemukan berkas rekam medis lama maka pasien menjadi pasien baru. Hal tersebut sudah sesuai dengan SOP No.272/SOP/UKP-8/2019 karena selama belum 2 tahun di rak inaktif rekam medis dapat digunakan kembali.

4. Setelah melakukan retensi selama 1 bulan, petugas menuliskan kegiatan retensi tersebut dibuku laporan kegiatan puskesmas. Hal tersebut sudah sesuai dengan SOP No.272/SOP/UKP-8/2019. 
Faktor Penyebab Ketidaksesuaian Standar Operasional Procedure Retensi Berkas Rekam Medis.

1. Jumlah Petugas

Sumber daya manusia atau SDM yaitu orang atau manusia yang diperlukan dalam sebuah organisasi yang bertujuan untuk menyelesaikan pekerjaan dalam waktu yang singkat sehingga meningkatkan efisiensi kinerja dan mencapai tujuannya [9].

Berdasarkan hasil wawancara dengan kepala rekam medis, jumlah petugas rekam medis yang tersedia di UPT Puskesmas Sukarasa adalah 5 orang. Dengan rincian:

1) Tiga orang petugas pendaftaran yang berpendidikan SMA, diantara tiga orang tersebut satuorang petugassudah menjadi PNS.

2) Dua orang petugas pelaporan dan pengolahan data yang berpendidikan D3 Rekam Medis.

Berdasarkan ketentuan PERMENKES nomor 31 pasal 28 ayat [3] Tahun 2019 Tentang Sistem Informasi Puskesmas. Anggota tim pengelola sebagaimana dimaksud pada ayat [1] paling sedikit 2 orang yang terdiri dari [10, p. 16]:

1) Tenaga kesehatan yang memiliki kompetensi epidemiologi atau statistik.

2) Tenaga non kesehatan yang memiliki kompetensi sistem informasi.

Tenaga kesehatan sudah sesusai dengan ketentuan permenkes, tetapi untuk pelaksanaan retensi rekam medis itu sendiri seharusnya ada petugas khusus retensi, sebab petugas kewalahan dalam melaksanakan retensi tersebut, dikarenakan jumlah berkas yang direntensi sejumlah $\leq 20.000$ berkas rekam medis. Menjadikan petugas tidak melaksanakan sesuai SOP dan adanya penataan ulang nomor rekam medis. Hal tersebut sering terjadi bahwa tidak adanya petugas khusus retensi dan faktor kesibukan dan keterbatasan waktu menjadi penyebab retensi sangat sulit dilakukan sesuai dengan SOP [11]. Melihat dari hasil penelitian bahwa dari 5 perekam medis yang memiliki latar belakang pendidikan rekam medis hanya 2 orang dan tidak ada petugas khusus sehingga perlu adanya peningkatan kemampuan melalui pelatihanpelatihan rekam medis yang berkaitan dengan retensi karena minimnya jumlah dan kompetensi SDM di bidang rekam medis kemungkinan akan menyebabkan terjadinya file hilang dan duplikasi berkas [12].

2. Tempat Penyimpanan Berkas Rekam Medis

Menurut Permenkes nomor 269 MENKES/PER/III/2008 tentang Rekam Medis Bab III, pasal 7 bahwa lembaga pelayanan kesehatan wajib menyediakan fasilitas yang dibutuhkan dalam rangka penyelenggaran rekam medis [7]. Fasilitas tersebut adalah media yang dibutuhkan dalam penyimpanan file rekam medis, seperti ruangan rekam medis yang memadai, rak penyimpanan yang besar, alat dan bahan yang dapat menunjang keutuhan serta melindungi rekam medis pasien. Dengan terpenuhinya hal tersebut terutama rak maka penyimpanan rekam medis dapat berjalan sesuai fungsinya. Selain itu berkas rekam medis menjadi lebih tertata rapi sehingga memudahkan dalam pengambilan rekam medis. Namun faktanya ruangan dan rak yang tersedia terbatas sehingga menjadi hambatan. Ruangan yang terbatas juga dapat menyebabkan terjadinya kesulitan dalam proses melayani dokumen rekam medis pasien [14]. Hal ini sejalan dengan hasil penelitian sebelumnya bahwa kendala pelaksanaan retensi diberbagai fasilitas pelayanan kesehatan diakibatkan karena penyimpanan rak aktif dan inaktif dalam satu ruangan [13].

Berdasarkan hasil wawancara dengan kepala rekam medis bahwa terdapat berkas rekam medis yang menumpuk dan tidak tersusun rapi di rak penyimpanan aktif, hal itu menjadikan petugas rekam medis perlu melakukan retensi berkas rekam medis dan pembaruan ulang nomor rekam medis supaya berkas rekam medis tersusun dengan rapi. Oleh sebab itu pelaksanaan retensi rekam medis tidak sesuai dengan Standar Operasional Prosedure karena tempat dan runagan yang kurang memadai. 
3. Jadwal Retensi di Puskemas.

Berdasarkan hasil wawancara dan analisis kebijakan SOP bahwa belum adanya jadwal retensi rekam medis yang ditetapkan. Sehingga ada berkas rekam medis yang belum mencapai masa simpan 2 tahun di rak aktif tetapi sudah di lakukan retensi dan dipindahkan ke rak inaktif. Hal tersebut tidak sesuai dengan Permenkes No.30 tahun 2012 tentang jadwal retensi arsip substantif dan fasilitatif non keuangan dan non kepegawaian di lingkungan kementerian Kesehatan pasal 1 ayat 2 yang menyatakan bahwa harus ada jadwal yang dijadikan sebagai pedoman dalam melakukan retensi rekam medis [15].

\section{KESIMPULAN}

Dari hasil penelitian ini penyusun menyimpulkan bahwa:

1. Belum adanya jadwal yang ditetapkan untuk pelaksaan retensi rekam medis sehingga tidak ada pedoman yang pasti mengenai waktu pelaksanaanya.

2. Retensi di UPT Puskesmas Sukarasa diatur dalam SOP No.272/SOP/UKP-8/2019 tentang "Penyusutan dan Pemusnahan Berkas Rekam Medis". Kebijakan tersebut berdasarkan pada Surat Keputusan Kepala Puskesmas Sukarasa. Didalam SOP tertulis bahwa berkas yang diretensi dilihat dari tanggal terakhir berobat, namun pada pelaksanaannya terdapat ketidaksesuaian karena berkas yang diretensi dilihat dari nomor tahun berkas rekam medis.

3. Tidak adanya petugas khusus yang melakukan retensi berkas rekam medis. Retensi di UPT Puskesmas Sukarasa hanya dilakukan oleh dua orang petugas, sedangkan berkas yang harus dipindahkan ke rak inaktif sangat banyak sehingga petugas yang merentensi memerlukan waktu yang cukup lama untuk memindahkan berkas tersebut ke rak penyimpanan inaktif.

4. Keterbatasan rak menjadikan berkas di rak penyimpanan aktif menumpuk dan tidak tersusun rapih. Sehingga pelaksanaan retensi harus segera dilakukan meskipun petugasnya terbatas. Kesulitan petugas pada saat mencarirekam medis yang akan digunakan juga menjadikan perlunya melakukan retensi aktif ke inaktif dengan jumlah yang cukup banyak, agar penumpukan berkas diruangan rekam medis aktif berkurang.

5. Berkas rekam medis inaktif disimpan di rak penyimpanan inaktif selama dua tahun, dan dapat digunakan kembali jika pasien masih memiliki nomor rekam medis yang lama, kemudian nomor rekam medis lama diganti dengan nomor yang baru karena sudah terjadi penataan dan pembaruan nomor rekam medis.

\section{REFERENCES}

[1] Depkes, "Manual Rekam Medis - Konsil Kedokteran Indonesia," Buku Man. Rekam Medis, 2006.

[2] Puskesmas Sukarasa, "Keputusan Kepala UPT Puskesmas Sukarasa nomor 014/SK1/UKP8/UPT PKM SKRS/2019 tentang Rekam Medis,” Bandung, 2019.

[3] Sugiyono, Metode Penelitian Pendidikan: Pendekatan Kuantitatif, Kualitatif, dan $R \& D$. Bandung: Alfabeta, 2010.

[4] Sugiyono, Metode Penelitian Kuantitatif, Kualitatif, Dan R\&D. Bandung: Alfabeta, 2017.

[5] Sugiyono, Metode Penelitian Pendidikan. Bandung: Alfabeta, 2015.

[6] M. M. Hikmat, Metode Penelitian: Dalam Pendekatan Praktis Penulisan Proposal dan Laporan Penelitian. Malang: UMM Press, 2011.

[7] Permenkes, "PERATURAN MENTERI KESEHATAN NOMER 269 TAHUN 2008 TENTANG REKAM MEDIS," Permenkes Ri No 269/Menkes/Per/Iii/2008. 2008.

[8] D. E. Sholikhah and N. M. Hastuti, "Pelaksanaan Retensi Dokumen Rekam Medis 
Aktif Dan In Aktif di RSUD K.R.M.T Wongsonegoro Semarang," J. Rekam Medis, vol. 11, no. 2, pp. 97-104, 2017.

[9] M. N. Almasri, "MANAJEMEN SUMBER DAYA MANUSIA: IMLEMENTASI DALAM PENDIDIKAN ISLAM M. Nazar Almasri," J. Penelit. Sos. keagamaan, 2016.

[10] Permenkes, "Peraturan Menteri Kesehatan Republik Indonesia Nomor 31 tahun 2019 tentang Sistem Informasi Puskesmas," vol. 8, no. 5, p. 55, 2019.

[11] E. Susanto et al., "Retensi Rekam Medis Dalam Upaya Efisiensi Rak Penyimpanan," Link, vol. 14, no. 2, p. 106, 2018, doi: 10.31983/link.v14i2.3770.

[12] D. Karlina, I. A. Putri, and D. B. Santoso, "Kejadian Misfile dan Duplikasi Berkas Rekam Medis Sebagai Pemicu Ketidaksinambungan Data Rekam Medis," J. Kesehat. Vokasional, vol. 1, no. 1, p. 44, 2016, doi: 10.22146/jkesvo.27477.

[13] E. Betri, "Analisa Pelaksaan Retensi Dokumen Rekam Medis Di Rsu Muhammadiyah Ponorogo," J. Delima Harapan, vol. 7, no. 2, pp. 86-91, 2020, doi: 10.31935/delima.v7i2.99.

[14] A. G. Pamboaji, "Analisis Pengelolaan Sumber Daya Unit Rekam Medis di Rumah Sakit Misi Lebak Guna Meningkatkan Efisensi dan Efektivitas Pelayanan," $J$. Kesehat. Vokasional, vol. 5, no. 3, p. 132, 2020, doi: 10.22146/jkesvo.48870.

[15] Permenkes, "Peraturan Menteri Kesehatan Nomor 30 Tahun 2012 tentang Jadwal Retensi Arsip Substantif Dan Fasilitatif Non Keuangan Dan Non Kepegawaian Di Lingkungan Kementerian Kesehatan,” no. July, p. 32, 2012.

\section{BIOGRAPHIES OF AUTHORS}

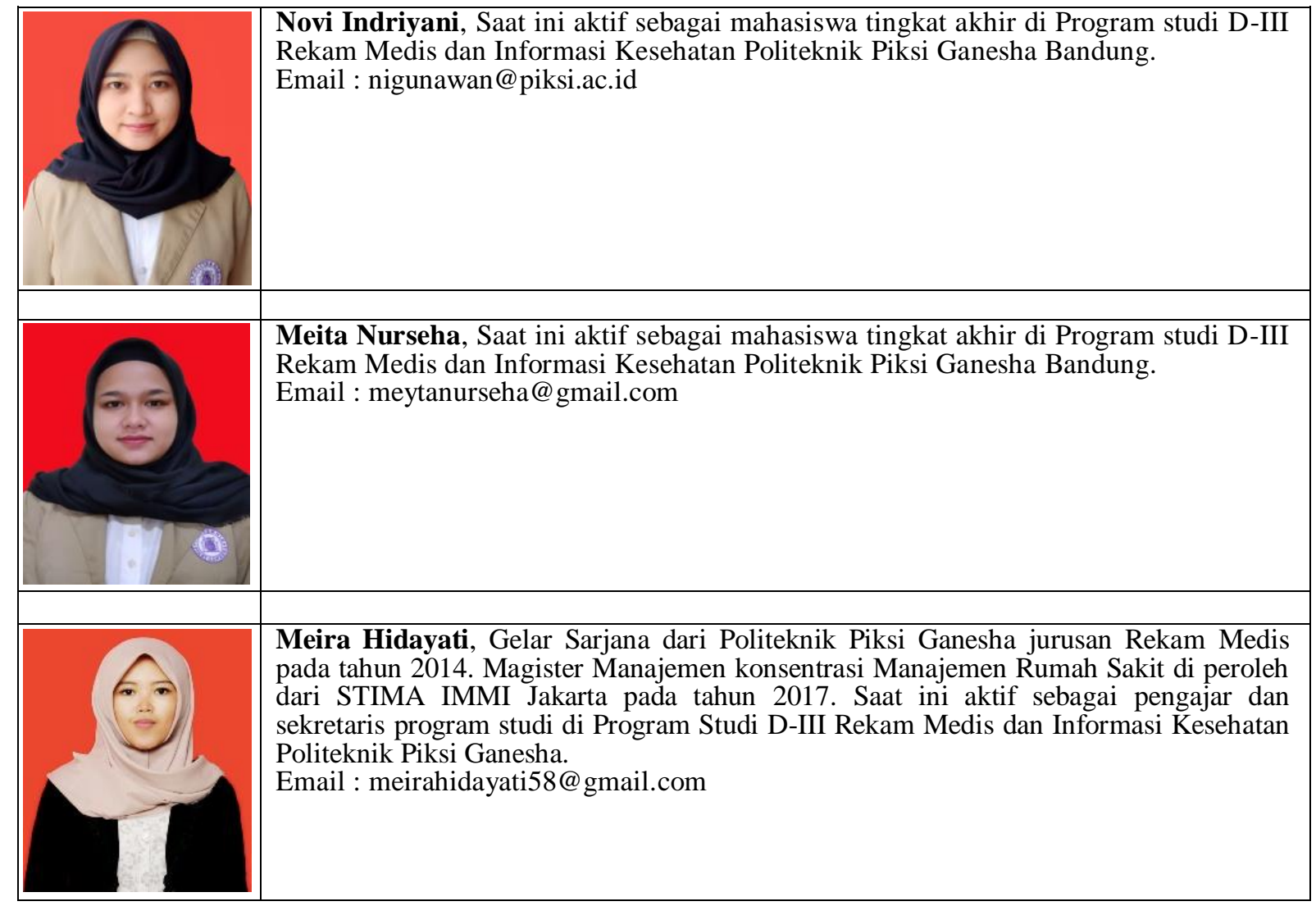

